\title{
A PERSPECTIVA HABERMASIANA NA INVESTIGAÇÃO CIENTÍFICA E A CONSTRUÇÃO DO CONHECIMENTO
}

\author{
Marilú Fontoura de Medeiros ${ }^{*}$
}

SÍNTESE - Na presente comunicação pretendemos refletir a produção de nossos objetos de pesquisa, tendo a Teoria da Ação Comunicativa como pano de fundo. Com base no desafio de desenvolvimento da autonomia e a construção socioindividual da liberdade - por si só um tema extenso e de complexidade, lançamos o debate acerca dos pressupostos habermasianos em áreas como formação de professores, universidade, avaliação e educação ambiental.
ABSTRACT - This work deals with reflexive thinking about the production of research objects based on Habermas' theory. Its concerning with the possibility of socioindividual construction of liberty and enlightenment in spite of this idea is considered by critics of critical theory of society as a utopy.

\section{1 - Para um início de conversa}

O tema proposto, "construção de conhecimento" ou "Habermas e a possibilidade da investigação científica", representa um desafio e um exercício extremamente ambíguo e contraditório. Por um lado, indica uma ousadia ao propor aplicações de uma teoria a um campo no qual o autor somente delineia processos e que, como tal, necessitam ser desenvolvidos e analisados com muita humildade; por outro lado, traduz um exercício de aplicação de uma teorização em processo, do pensamento de um autor - Jürgen Habermas - que a cada dia gesta uma nova idéia ou apresenta o uso diferenciado dado a uma nova/velha idéia.

Ressalto que o atributo habermasiano apresentado no título do trabalho indica a busca continuada de entendimento do pensamento do autor em sua própria gênese e do entendimento que faço do "estado de coisas" em sua teorização e em sua prática. A busca do nexo entre teoria e prática,através da leitura de suas obras, no explícito e no implícito, têm sido um dos grandes desafios a que tenho procurado responder.

Prof. Titular em educação. Doutor em Ciências Humanas pela UFRGS. Professora pesquisadora do CNPq do Programa de Pós-Graduação em Educação da Fac. de Educação da PUCRS.

\begin{tabular}{|l|l|l|l|l|l|}
\hline VERITAS & Porto Alegre & v. 41 & $\mathrm{n}^{\circ} 162$ & Junho 1996 & p. 281-290 \\
\hline
\end{tabular}


Apresentada a ambigüidade ou a moldura com que me deparei ao escrever sobre o tema, gostaria de propor um grande foco para o exame da possivel aplicação das idéias de Habermas ao trabalho educativo, qual seja: onde e como se situa a subjetividade, a intersubjetividade e a autonomia nos contextos socioeducativos? são possiveis essas categorias históricas? E, como tal, qual(is) a (s) sua(s) inserção(ções) a partir do foco e dos eixos que apresentamos para norteamento das análises e ações?

A partir da ótica de um educador, situarei como temos trabalhado esses focos em seus conceitos, fatores, o que temos refletido acerca deles/neles e o que encontramos de possibilidades/impossibilidades na prática pedagógica. No entanto, para que tais fatores possam ser melhor compreendidos no amplo processo de construção do conhecimentro, considero fundamental delinear algumas dimensões do pensamento habermasiano apreendidas em minhas leituras:

- como princípio maior em sua dificuldade, desafio e possibilidade, a retomada das dimensões de liberdade e de democracia, e, nelas, a exigência do espaço público, da necessidade de inserção de todos os sujeitos na fala e da legitimidade da soberania popular argumentativamente construída (Medeiros, 1995, 1995a, 1995b, 1996; Medeiros e Lovatel, 1995);

- a guinada paradigmática e a guinada lingüística (Medeiros, 1994; Aragão, 1992) nas quais Habermas retrabalha a questão do sujeito e propõe a superação do paradigma do sujeito e da consciência para um paradigma da comunicação e da linguagem dialogicamente estabelecido entre pares, mesmo que desiguais e diferenciados, linguagem essa que abre perspectivas para a possivel construção do "eu" e do "outro", em um patamar qualitativamente diferenciado, fundado em visões descentradas de si mesmo e do outro;

- a retomada da dimensão da subjetividade, ressignificada pela presença do outro na perspectiva da intersubjetividade, mediada pela linguagem e pela idéia de que o "Eu", dialeticamente, só existe em função do Outro (Medeiros, 1994; Medeiros e Colla, 1994);

- a ênfase nos interesses que norteiam o uso do conhecimento, as racionalidades, frente às lógicas enfatizadas no mundo da vida e no mundo do sistema ( $\mathrm{Me}$ deiros, 1994; Medeiros e Colla, 1994a, b);

- o destaque aos nexos entre teoria e prática decorrentes do desvelamento ideológico dos interesses que orientam o uso do conhecimento, nexos estes a que denominamos como uma lógica interna (Medeiros, 1995, 1995a) que dirigem, consciente ou inconscientemente, a ação dos indivíduos ou grupos;

- a retomada de um conceito mediador altamente significativo para a constituição da democracia e da liberdade, situados no que o autor denomina como espaço público e formação da vontade coletiva ou soberana (Medeiros, 1993; 1995, 1995b).

Além das dimensões enfatizadas, julgo relevante destacar, tão relevante quanto as demais para o exercício da ação comunicativa, idéias como:

- a recusa de qualquer fundamentalismo, seja ele de ordem religiosa, filosófica ou político-partidária (Habermas, 1988; 1990);

- a gênese teórico-prática, como filósofo que incursiona pelas mais diferentes áreas, situadas simplificadamente em vertentes decorrentes da hermenêutica, da 
psicanálise e do materialismo histórico (Habermas, 1987a; 1984; 1988; 1990; 1990a), além da inclusão das influências advindas do interacionismo simbólico, da psicogenética, da teoria dos atos de fala (Habermas, 1989; 1990b);

- das análises e críticas a que se propõe tanto junto ao capitalismo como ao socialismo burocrático e, principalmente, sua coragem em exercer a crítica a partir de dentro, inclusive, de si mesmo, não tendo o receio de enfrentá-la, superando os maniqueísmos presentes no "e/ou", assumindo o "isto $\mathrm{E}$ aquilo" (Habermas, 1990; 1993; 1995);

- sua clara noção de que as microações com a visão da totalidade são tão relevantes quanto as macroações para a construção da transformação socioindividual e para a construção da liberdade (Habermas, 1990 a; 1991, 1992).

Delineada a figura que percebo do autor, compartilho o que temos construído como objetos de pesquisa em uma relação contraditória e difícil, na qual se concretiza um jogo entre sujeitos e objetos, interesses e conhecimento, jogo esse não dicotomizado e visualizado tanto no que está presente como no que está implícito na ação.

No mínimo, cinco projetos resultaram ao longo de nossa caminhada, contemplando algumas dessas dimensões e tendo como foco a autonomia e a liberdade, como chances para espaços democraticamente estabelecidos: um deles trata das relações de poder estabelecidas no trabalho da universidade com os demais graus de ensino (Medeiros, Colla e Martins, 1993); um segundo diz respeito à proposta de um paradigma de avaliação emancipatória na prática de construção e análise de um currículo/curso (Klein, Lovatel e Medeiros, 1993, 1993a); outros abordam a questão das racionalidades que orientam as ações e o uso do conhecimento no que se refere à educação ambiental (Medeiros, Ribeiro, Kronbauer, 1994) e, ainda, tratam do uso do conhecimento em áreas específicas do conhecimento no exercício de atividades profissionais (Paskulin, 1993; Cogo, 1994).

Embora os objetos tenham toda uma especificidade a ser respeitada em função de suas naturezas, há como que um fio condutor nestas investigações, qual seja o adentramento em dimensões da teoria habermasiana.

De qualquer modo, o que nos propomos trazer aqui são as condições pelas quais temos construído objetos de pesquisa em diferentes áreas e niveis, estabelecendo os meandros que nos permitem chegar a tal e como, na grande parte das vezes, temos que estabelecer outros elos, propor rupturas e/ou questionar certas premissas.

\section{2 - O "Objeto" Universidade: interesses e uso do conhecimento}

Quando trabalhamos com o objeto universidade, formação de professores, subjetividade e autonomia deparamo-nos obviamente com questões relacionadas ao poder e à emancipação. Ao iniciar o processo de construção do objeto de pesquisa, detectamos uma realidade não presente ou explicitada; havia como que um velamento ideológico acerca do âmago das ações desenvolvidas pela universidade. As tradicionais relações de dominação entre classes não respondiam às nossas indagações. Uma outra realidade emergia. 
Observamos que nessas relações entre a universidade, seus sujeitos concretos e a comunidade de escolas de outros graus, a universidade trazia espaços permanentes, simultâneos e contraditórios de autonomização, de dominação e de pseudo autonomização. Uma lógica não pensada se delineava: uma aparente distância entre o dito e o feito pela universidade e pelas escolas demonstrava não ser essa tão aparente e nem tão distante, uma vez que essa suposta distância evidenciavam outras lógicas que não as tradicionalmente propostas ou defendidas pelos responsáveis em cada projeto (Habermas, 1987; 1982).

Nessas lógicas se apresentavam, às vezes, simultaneamente e no mesmo sujeito, os dois mundos, sendo um deles representado pelo "mundo vivido" com suas possibilidades de transformação e de construção da liberdade, e um outro que defendia uma lógica de domínio e de poder, representando o "mundo do sistema" (Habermas, 1988,1990). Não era, ou não era somente, uma relação de dominantes e dominados maniqueisticamente definida. Tratava-se, sobretudo, de uma relação entre um fazer e uma lógica a que denominamos "lógica interna", tal como Austin (1992) defende e no que Habermas (1988; 1989; 1990a) concorda com a expressão empregada por Austin: "quando o dizer é fazer".

Podemos estar propondo uma ação estritamente democrática, mas, se a estivermos fazendo com uma condição fascista, de sedução, de cooptação ou de coerção, de maneira alguma estaremos vivenciando uma proposta democrática. Não podemos construir um ato que se institua quer como ação técnica-instrumental (mesmo que em nome do bem-estar da coletividade e do cumprimento da ordem mais banal), quer como ação estratégica (na qual tentamos convencer o outro da legitimidade de certos ordenamentos, sem questioná-los) em nome de uma ação emancipatória. Esse tipo de ação nada tem de emancipatório (Habermas, 1987 a,b; 1982; 1988; 1989).

Em um dos projetos examinados, de uma universidade de São Paulo, observamos não só a denúncia, como o trabalho com o primeiro grau de ensino em uma relação de iguais, iguais diferenciados. No exame do material detectamos o objetivo de fazer do/com o aluno de primeira série um produtor e criador de textos. 0 grupo de pesquisadores explora com os professores as produções dos alunos e a forma como a escola avalia essas produções: em um deles, o aluno apresenta uma escrita correta, formal e estereotipada (do tipo "A bola é bonita". A bola é vermelha. A bola é do menino") e este é aprovado para avançar em seus estudos; em um segundo caso, um aluno produz uma história rica com significado e este aluno foi reprovado porque embora fosse capaz de ler, de escrever um material com conteúdo, não o fez na modalidade ou vertente padrão da língua denominada como culta. A lógica da exclusão é, mais uma vez, privilegiada, mesmo que velada, sob o argumento de que o segundo aluno não está alfabetizado. É sobre essa estrutura que 0 grupo da universidade refletiu com a escola, buscando reverter o quadro publicizado (falsamente), desvelando as contradições entre o dito, o proclamado e o feito na prática, concreta (Habermas, 1984, 1987b; 1990 a).

Ao construir o objeto de pesquisa do trabalho da universidade para (com) as escolas nos obrigamos a adentrar para o interior das ações e dos atos de fala (Habermas, 1988; 1989;1990; 1993) desvelando ideologicamente os reais interesses que orientavam aqueles atos de fala. Desse mọdo, embora considerando o exemplo su- 
pracitado e de outros relatados ao longo do relatório de pesquisa (Medeiros, Colla e Martins, 1993), verificamos que a ação emancipatória da (na) universidade se dá, ainda, em pequenos "nichos", em "minorias marginais" (Habermas, 1993), apesar de teoricamente defendida por uma maioria quase que absoluta. A universidade se julga progressista, acusa os demais de não o serem, mas não enfrenta uma questão fundamental, para a qual necessita romper com o corporativismo e com o fundamentalismo essencialmente político-partidário, como a de "refletir a sua própria ação", "refletindo com o outro" (Habermas, 1988; 1989; 1990). Essa postura implica em assumir, na prática, um conceito hoje representado pela opacidade (Habermas, 1987b), qual seja, o de espaço público. Habermas (1984),

\section{3 - O "Objeto " Gestão Democrática: legitimidade da ordem}

Quando lidamos com questões teórico-práticas de construção de contextos democráticos, argumentativamente estabelecidos, observamos, em primeiro lugar, a necessidade e a presença do nexo entre teoria e prática, mesmo que velado e inconsciente. Não bastava dedicar-se a perscrutar o falar, necessitava-se captar o fazer para, nele, deixar evidente o real nexo entre teoria e prática. A lógica interna emergia dessa luta.

No processo de construção do objeto de pesquisa acerca da gestão democrática (Klein, Lovatel e Medeiros, 1993a, b; Lovatel, Klein e Medeiros, 1995; Medeiros, 1995), além das dimensões relacionadas à lógica interna ou racionalidades, aos mundos vivido e do sistema em suas necessárias intersecções, ao desvelamento dos reais interesses que norteiam a ação no uso cotidiano do conhecimento, outras pressuposições ou temáticas emergiram. A principal delas, em nossa percepção, diz respeito ao que Habermas (1984, 1990) denomina como o processo de "legitimação da ordem" (Freitag e Rouanet, 1995).

A legitimidade representa, segundo Habermas (1990b, p. 106), "um ato intersubjetivo do qual resulta a perspectiva da primeira pessoa do plural [a construção de um nós] de uma comunidade contrafaticamente ampliada". Sem representar a ditadura da maioria, em contraposição à tradicional ditadura da minoria (!), vivenciamos situações nas quais todos, sem pré-julgamentos, tivessem condições de ser ouvidos e acatados no que representa de benéfico para todos/ para o coletivo, assim como para cada um, individualmente. A instauração processual da legitimidade da ordem permitiu-nos, não sem dificuldades, questionar as decisões que não se mostravam verazes, verdadeiras ou justas para a maioria; entretanto, essa mesma legitimidade não se instaura sem um permanente e dialético processo entre os interesses de todos e de cada um. Cabia, na prática, a cada um de nós o questionamento de como conciliar os interesses individuais com os de todos e vice-versa (Lovatel, Klein e Medeiros, 1994).

Esse foi o processo mais arduamente vivido na estrutura de pesquisa e na construção do próprio objeto de investigação, uma vez que, nele, mais cruamente se evidenciavam as contradições entre cada um e o todo e o jogo de poder/emancipação daí decorrente. No entanto, se nossa proposta se situa na moldura da democracia é por este "buraco da agulha", como afirma Habermas (1991), que tais ações necessitam passar. A construção radical da democracia, seja do Estado, seja dos 
sujeitos individualmente considerados, seja dos grupos organizados na denominada sociedade civil, passa pela permanente e processual tematização acerca da legitimidade.

Não há ordem estabelecida como verdadeira e legitima se a ela não corresponder alguns pressupostos centrados na autenticidade do sujeito, na expressão da verdade argumentativamente aceita e na justiça dessas mesmas normas em relação a cada um e a todos, tanto em seus meios quanto em seus fins.

No caso em questão,

\begin{abstract}
"a proposta pedagógica do curso objeto da pesquisa foi visualizada na sua parcialidade/totalidade, quando temas polêmicos foram analisados e avaliados sob óticas diferenciadas, em um espaço de não-coerção e de não-violência [...]. Nos momentos de vivência do agir comunicativo ou sua aproximação virtual surgiram pretensões de verdades ensejadoras de modificaçōes que podem ser expostas a um novo processo de validação, via discurso argumentativo e questionamento de validades estabelecidas [...] no sentido do desvelamento ideológico, com vistas à construção de uma realidade mais legítima e autônoma." (Medeiros, 1995, p.2930).
\end{abstract}

Legitimidade, como uma categoria histórica (Habermas, 1984, 1990b), é vinculada em sua dimensão reconstrutivista, significando a busca argumentativa para que um ordenamento político seja digno de ser reconhecido, assumido em sua validade contestável (Medeiros, 1995b). Nessa perspectiva, (Medeiros, 1987; 1994), essa dimensão caracteriza-se pela multiplicidade de interlocutores que buscam juntos, pela palavra, tornar transparentes os contextos internos e externos de dominação, tematizando verdades nas esferas fatuais, sociais e das vivências, com vistas a um mundo legitimado pela própria dinâmica de construção processual da verdade, na qual meios e fins podem e devem ser questionados quando não se mostrarem legítimos para cada um e para todos, expresso por Habermas (1990b)

\title{
4 - O "Objeto" Avaliação Emancipatória: ética discursiva
}

Ao trabalharmos esse eixo de forma mais explícita, qual seja o da tentativa de concretização dos princípios da ética discursiva (Apel, 1994; Habermas, 1989,1990b), lidamos com dois grupos de pesquisa: um deles é destacado neste eixo e trata da construção na prática de um paradigma de avaliação emancipatória (Klein, Lovatel e Medeiros, 1993; Medeiros, 1995); o outro, trata dos processos ideológicos inerentes à educação ambiental (Medeiros, Ribeiro e Kronbauer, 1994; Medeiros, Biaggio, Ribeiro e Kronbauer, 1995). Como já afirmamos, não há como tratar de partes da teoria. A descrição neste texto é, assim, empregada com um único propósito de dar destaque a algumas idéias consideradas centrais e que melhor podem ser explicadas junto à exploração de determinado eixo.

A construção do parađigma de avaliação emancipatória pressupõe, entre outros itens e fatores, a idéia de tematização da legitimidade e da própria democracia. Entendemos democracia radical como parte de um processo de comunicação política ou de ação intersubjetiva que se desenvolve com ausência de violência, em uma moldura argumentativa, na qual são contemplados tanto o dissenso quanto 0 consenso. Nesse processo, são levantadas pretensões de verdade que envolvem um desenvolvimento compartilhado e responsável entre as perspectivas do "Eu", do "Tu" e da construção do "Outro" qualitativamente diferenciada. 
Representa (ou) uma luta cotidiana de conquista que só se substantiva em uma clivagem de argumentação livre de coerção, com transparência, com uso de espaços públicos e de campos de ressonância desses espaços e processos.

O processo avaliativo, por nós construído na pesquisa,

"tem como pressupostos teórico-metodológicos principios habermasianos, fundados no (a): (1) busca de uma comunidade de comunicação, com o intuito de tematizar, questionar vivências, fatos e/ou normas na perspectiva de atos de fala que inclua o "eu", o "tu" e o "outro"; (2) inclusão de "todos e de cada um" em espaços públicos, como condição de construção, consolidação e aperfeiçoamento da radicalidade do processo democrático; (3) aceitação dos contrários e da diferença no espaço público, de transparência, visando o embate no uso do conhecimento/tematização das verdades, desvelando seus reais interesses, sem coação, coerção, cooptação; (4) valor do discurso argumentativo e da não violência, mesmo que simbólica; (5) desvelamento ideológico das contradições e da "lógica interna" no uso do conhecimento, desocultando os reais interesses e, nesse processo, o desocultamento do ilegítimo pelas suas dimensöes de inautenticidade/autenticidade, verdade/inverdade, justo/injusto; (6) assunção da reflexão não como monólogo reflexivo, mas como processo que se instaura com o outro, em uma ação descentrada, intersubjetiva; (7) critica dialética em oposição à crítica dogmática; (8) construção socioindividual da liberdade como mediadora e resultante de um processo emancipatório, autônomo, crítico e reflexivo, construindo uma sociedade processualisticamente mais legitima" (Klein, Lovatel e Medeiros, 1993, p. 113; Medeiros, 1995d, p. 20).

Algo que aprendemos de essencial nesse processo foi procurar diferenciar o uso da crítica dogmática e da crítica dialética. Enquanto a crítica dogmática busca impor a sua própria visão ao objeto criticado, a crítica dialética, diferente da anterior que oprime a quem é criticado, procura libertar tanto quem critica como quem é criticado.

\section{5 - 0 "Objeto " educação ambiental: subjetividade/intersubjetividade}

Na construção desse objeto de pesquisa - a educação ambiental em suas mediações com a qualidade de vida de todos e de cada um, com o nivel de competência e de desenvolvimento da competência do eu - trabalhamos com fundamentos presentes na ética discursiva (Apel, 1994; Habermas, 1989, 1990b) e que se fundam nos pressupostos de desenvolvimento moral propostos por Piaget e Kohlberg. Nesse sentido, Habermas (1990 b) explora a caminhada do homem, de todos e de cada um, da ausência de normas passando pela heteronomia até a autonomia. A saída da minoridade para a maioridade, a emancipação, exige competências processualizadas em niveis lingüísticos, cognitivos e morais. É sobre essa permanente busca e essa processualidade de um princípio universal (U) que nos debruçamos no exame das propostas existentes em termos da Educação Ambiental (Medeiros, Biaggio, Ribeiro, Kronbauer, 1995). Uma de nossas questões-chave centra-se na tematização da autenticidade, verdade e justiça das idéias defendidas nessa área. Em que medida elas realmente expressam o desejo de todos e dos que mais dela necessitam? Ou, em que medida essas propostas servem a poucos, em nome da coletividade, representando, assim, uma nova roupagem ideológica? (Medeiros, Ribeiro, Kronbauer, 1994). 
Em um dos trabalhos destacados, questionamos, exatamente, essa questão ideológica atrelada à educação ambiental, incluindo o oportunismo que ela promove (Medeiros, Ribeiro e Kronbauer, 1994, p. 114):

"[...] Isto significa que as relações são cada vez mais próximas e diretas na "ideologização da aldeia global", em termos de ações, fatores, conseqüências e usos dos outros como objeto via dominação, persuasão, cooptação, todas faces da mesma moeda de falsa legitimação que o velamento ideológico e a restrição das esferas públicas propiciam. Cada vez mais a ordem mundial - ou a suposta nova ordem mundial - atropela, subjuga, territorializa subjetivamente, desautonomiza, deixando-nos o sentimento que Weffort (1992) chamou de perda de lugar no mundo sentido pela América Latina e pelos paises do hoje denominado como Terceiro Mundo. Novos blocos de poder, assentados na modernização e na lógica capitalística, representados pela Nova Direita, travestem palavras de ordem e de relações de sobrevivência: como se fosse em nome de todos, universalizam interesses particulares de um determinado grupo. É nesse cenário de "descarte-encaixe" da América Latina que o discurso ambiental se posta. Afinal, a quem ele serve? Qual a categoria que o orienta..."

Lidamos com as produções dos denominados experts na área, buscando detectar a direção e o nivel de desenvolvimento de suas propostas em termos da coletividade e da democracia-cidadã e crítica. Buscamos, além disso, captar como essas produções contemplam temas candentes dentro da área de Educação Ambiental, tais como vertentes explicitadas pelo verdismo, salvacionismo ou questões como desenvolvimento auto-sustentável, ordem mundial e global integrada, qualidade de vida, uso de um ser sobre outro, fome, miséria, espécies em extinção, entre outras.

Os dados até então examinados nos têm permitido detectar um nível de preocupação com as necessidades e expectativas de todos, embora alguns fatores emerjam como parte de uma perspectiva individualista, nem sempre consciente. Tais fatores estão, em sua maioria, atrelados a uma ordem mundial integrada, com um mínimo de questionamento socializador.

\section{6 - À guisa de conclusão}

Como já explicitamos no início do trabalho, em nossa percepção, não é fácil trabalhar com as propostas deduzidas da teoria crítica de sociedade de Habermas por dois motivos. Afora o que filósofos apresentam como crítica a Habermas sobre a falta de uma ontologia do ser, em nossa leitura, os fatores que mais perturbam a sua aplicabilidade situam-se na processualidade de sua produção, uma vez que se trata da gestação de idéias de um autor que continua produzindo e, segundo, o que é mais importante a nosso ver, é o de que não podemos dar aplicação a suas idéias sem estarmos comprometidos com o necessário nexo entre teoria e prática, entre os interesses que dizemos defender e os que realmente defendemos. Esse nexo exige do sujeito uma ação eminentemente dialógica e intersubjetiva, que se baseia na busca de verdades construídas/conquistadas argumentativamente e não postadas normativamente como verdades únicas. Implica em buscar ser o que dizemos que somos ou o que lutamos para ser!

Desse modo, a construção do conhecimento, a produção de verdades no campo das vivências, das normas, dos fatos exige uma postura que se pontue pela democracia processualisticamente instituinte. 
Ainda merece destaque outro nível de aplicação dos pressupostos habermasianos à construção do conhecimento . Esses residem na ressignificação de uma ferramenta, a análise de discurso (Medeiros, 1995 c; 1996), como base não só para a construção de uma democracia radical, mas também para testar e gestar a formação de um discurso centrado na intersubjetividade e na busca permanente da verdade, construido em bases dialógicas.

\section{7 - Referências bibliografícas}

APEL, Karl Otto. Estudo de moral moderna. Petrópolis: Vozes, 1994.

ARAGÃO, Lúcia Maria de Carvalho. Razão comunicativa e teoria social crítica em Jürgen Habermas.

Rio de Janeiro: Tempo Brasileiro, 1992.

AUSTIN, John L. Quando dizer é fazer. Porto Alegre: Artes Médicas, 1992.

COGO, Ana Luiza. 1994. A qualificação profissional de auxiliares de enfermagem e as racionalidades.

Porto Alegre: PPGEDUC/PUCRS, 1994.

FREITAG, Bárbara \& ROUANET, Sérgio Paulo (entrevs.). "Conversa com Habermas". São Paulo: Folha de

São Paulo, Caderno 5, MAIS, 30 de abril, p. 4-10, 1995.

HABERMAS, Jürgen. Conhecimento e Interesse. Rio de Janeiro: Tempo Brasileiro, 1992.

—_. Mudança estrutural da esfera pública. Rio de Janeiro: Tempo Brasileiro, 1984.

— Técnica e ciência como ideologia. Porto: Ediçōes 70, 1987.

—_ . "A nova intransparência". São Paulo: Novos Estudos CEPRAP, 18:103-114, 1987b.

—_. Teoria de la acción comunicativa. Madrid: Taurus, volumes I e II, 1988.

— Consciência moral e agir comunicativo. Rio de Janeiro: Tempo Brasileiro, 1989.

—— . O discurso filosófico da modernidade. Lisboa: Dom Quixote, 1990.

- _ Pensamento pós-metafísico. Rio de Janeiro: Tempo Brasileiro, 1990a.

—_. Para a reconstrução do materialismo histórico. São Paulo: Brasilense, 1990 b.

——. "Que significa socialismo hoje? revolução recuperadora e necessidade de revisão da esquerda". São Paulo: Novos Estudos CEBRAP, n. 30: 43-61, 1991.

—— . "A revolução e a necessidade de revisão na esquerda - o que significa socialismo hoje?" In: BLACKBURN, Robin (org.). Depois da queda: o fracasso do comunismo e o futuro do socialismo. Rio de Janeiro: Paz e Terra, 1992.

— . O passado como futuro. Rio de Janeiro: Tempo Brasileiro, 1993.

—_ . "Conversa com Habermas" (Bárbara Freitag \& Sérgio Paulo Rouanet, entrevistadores) São Paulo: Folha de São Paulo, Caderno 5, MAIS, 30 de abril, p. 4-10, 1995.

KLEIN, Maria Helena Córdova; LOVATEL, Tereza Hoffmeister e MEDEIROS, Marilú Fontoura de. "Construindo um processo avaliativo crítico e emancipatório: resultados parciais de uma pesquisa avaliativa". Estudos em Avaliação Educacional. São Paulo: Fundação Carlos Chagas, 7: 133-148, 1993.

KLEIN, Maria Helena Córdova; LOVATEL, Tereza Hoffmeister e MEDEIROS, Marilú Fontoura de. "Construindo um processo avaliativo pela via da ação comunicativa, crítica e emancipatória e suas possibilidades em um Curso de formação de especialistas em educação". Relatório de pesquisa. Porto Alegre: UFRGS e PUCRS, 1993a.

LOVATEL, Tereza Hoffmeister; KLEIN, Maria Helena Córdova e MEDEIROS, Marilú Fontoura de. "Formação do educador-especialista: possibilidades e contradições emergentes da construção de uma proposta avaliativa, critica e reflexiva como suporte para o processo emancipatório socioindividual". Consciência. Palmas: 8 (2): 7-26, jul./dez., 1994.

MEDEIROS, Marilú Fontoura de. "As possibilidades do pensamento habermasiano e a prática pedagógica: uma tentativa de entendimento". Educação. Porto Alegre: EDIPUCRS, XVI (25): 217-244, 1993.

MEDEIROS, Marilú Fontoura de; COLLA, Anamaria Lopes e MARTINS, Ana Maria Petersen. "Paradigmas ideológicos do trabalho da universidade com $\circ 1^{2}$ grau de ensino: a universidade faz uma práxis do discurso que apresenta?". Porto Alegre: PUCRS/UFRGS, CNPq, Relatório de pesquisa, 1993

MEDEIROS, Gilberto Mucilo de. O processo de modernidade e a universidade brasileira: tendências emancipatórias. Porto Alegre: PPGEDUC/PUCRS, tese de doutorado, 1994. 
MEDEIROS, Marilú Fontoura de; RIBEIRO, Eros; KRONBAUER, Ruth Ignácio. "Uma visão crítica da educação ou só uma roupagem ideológica". Revista Portuguesa de Educação. Braga: Universidade do Minho, 7 (1/2): 113-126, 1994.

—_. "Eixos emergentes na proposta habermasiana e a possibilidade da ação pedagógica crítica e reflexiva". Educação e Filosofia. Uberlândia: UBUb, 8 (15): 49-65, jan./jun., 1994.

—_. . e COLLA, Anamaria Lopes. "A universidade no espelho: haverá alguém mais progressista do que eu?" Caxambu, Minas Gerais: Reunião Anual da ANPEd. Anais TRABALHO, 23-28, out., 1994.

— . e COLLA, Anamaria Lopes. "Ciência, técnica e os nexos entre teoria e prática". Tecnologia Educacional. Rio de Janeiro: ABT, 22 (116/117): 9-21, jan./fev./abr., 1994a.

- ; BIAGGIO, Angela; RIBEIRO, Eros e KRONBAUER, Ruth Ignácio. "Educação Ambiental: Subjetividade, cidadania e desenvolvimento moral". Aprovado com reformulações para publicação em $\mathrm{Ca}$ dernos de Pesquisa. São Paulo: FCC, 1995.

— . "A modernidade e a transformação da administração da educação na direção de uma ação critica e emancipatória". Cadernos CEDAE, Porto Alegre: ANPAE, 2, (2):13-36, 1995.

—_ - "Esfera pública, soberania e cidadania como possibilidade socioindividual de formação geral da vontade". Porto Alegre: PUCRS (encaminhado para Educação e Sociedade), $1995 \mathrm{a}$.

. "Paradigma de avaliação emancipatória e a ação supervisora: cidadania e espaço público". In: RANGEL, Mary (org.). Supervisâo e crítica. Rio de Janeiro: Vozes, 1995b (no prelo).

. "Ressignificando a Análise do Discurso na perspectiva habermasiana". In: GRILLO, Marlene e MEDEIROS, Marilú Fontoura de (orgs.). Construindo os meandros do objeto de pesquisa. (título provisório). Porto Alegre: PPGEDUCAÇÃO/PUCRS, (a ser submetido à EDIPUCRS), 1995c.

. "Paradigma de avaliação emancipatória, cidadania e espaço público". Educação. Porto Alegre: PUCRS, ano XVIII, n. 29:7-30, 1995 d.

\& LOVATEL, Tereza Hoffmeister. "A prática da coordenação de ações num curso de formação de educadores/especialistas: avanços e recuos em busca da modemidade em administração". Cadernos CEDAE, Porto Alegre: ANPAE, 2, (2):37-46, 1995.

. "Como uma nebulosa... ou a perspectiva habermasiana na construção do conhecimento: a análise de discurso". 1996 In: MORAES, Roque \& MEDEIROS, Marilú Fontoura de (orgs.). Análise de conteúdo e análise de discurso: homologias, diferenciações e ressignificaçōes. Porto Alegre: EDIPUCRS, 1996 (em processo de exame e possivel aprovação).

. "Habermas: um autor". In: SEVERINO, Joaquim (org.). Grandes teóricos e a educação. Rio de Janeiro: Vozes, 1995 (no prelo).

PASKULIN, Lisiane. A formação na enfermagem e a teoria crítica. Porto Alegre: PPGEDUC/PUCRS, 1993. 